\title{
2.4 GHZ, 5W, GAN HEMT AB SINIFI GÜÇ KUVVETLENDIRICISI TASARIMI
}

Kaan KULA (kulakaa@itu.edu.tr)

İstanbul Teknik Üniversitesi, Elektrik Elektronik Fakültesi, Elektronik ve Haberleşme Mühendisliği Bölümü, İstanbul, Türkiye

Osman CEYLAN (ceylanos@itu.edu.tr) İstanbul Teknik Üniversitesi, Elektrik Elektronik Fakültesi, Elektronik ve Haberleşme Mühendisliği Bölümü, İstanbul, Türkiye

Hasan Bülent YAĞCI (bulent.yagci@itu.edu.tr) İstanbul Teknik Üniversitesi, Elektrik Elektronik Fakültesi, Elektronik ve Haberleşme Mühendisliği Bölümü, İstanbul, Türkiye

\section{ÖZET}

$\mathrm{Bu}$ çalışmada $2.4 \mathrm{GHz}$ frekansında $5 \mathrm{~W}$ çıkış gücüne sahip $\mathrm{AB}$ sınıfı bir güç kuvvetlendiricisi tasarlanmış ve gerçeklenmiştir. Tasarımda Sumitomo Electric firmasının SGNE010MK GaN HEMT'i kullanılmıştır. Firma tarafından sağlanan doğrusal olmayan model ile bilgisayar destekli analiz ve tasarım yapılmıştır. Taban olarak Taconic firmasının $0.76 \mathrm{~mm}$ kalınlığında, dielektrik katsayısı 3 olan TSM-DS3 tabanı kullanılmıştır. Tasarlanan kuvvetlendiricinin, sürekli dalga işaret ile $5 \mathrm{~W}$ çıkış gücünde en yüksek eklenmiş verimi $\% 44$ olarak ölçülmüştür ve 50 $\mathrm{MHz}$ bant genişliğinde $\% 40$ üzerinde verime sahiptir. Elde edilen sonuçlara göre, tasarlanan kuvvetlendirici aynı tranzistör ile tasarlanmış olan raporlanmış $\mathrm{AB}$ sınıfı güç kuvvetlendiricilerine göre daha yüksek frekansta daha yüksek verime sahiptir.

Anahtar Kelimeler: GaN HEMT, RF Güç Kuvvetlendiricisi, AB Sinıfi

Kuvvetlendirici. 


\title{
2.4 GHZ 5W GAN HEMT CLASS AB RF POWER AMPLIFIER DESIGN
}

Kaan KULA (kulakaa@itu.edu.tr)

Istanbul Technical University, Electrical - Electronics Faculty, Electronics and Communication Engineering Department, Istanbul, Turkey

Osman CEYLAN (ceylanos@itu.edu.tr) Istanbul Technical University, Electrical - Electronics Faculty, Electronics and Communication Engineering Department, Istanbul, Turkey

Hasan Bülent YAĞCI (bulent.yagci@itu.edu.tr) Istanbul Technical University, Electrical - Electronics Faculty, Electronics and Communication Engineering Department, Istanbul, Turkey

\begin{abstract}
In this study, a $5 \mathrm{~W}$ class $\mathrm{AB} \mathrm{RF}$ power amplifier at $2.4 \mathrm{GHz}$ is presented. Sumitomo Electric's SGNE010MK transistor was preferred for the design. Nonlinear GaN HEMT model for EDA tools was used at the design procedure which is provided by Sumitomo Electric. Taconic TSM-DS3 with $0.76 \mathrm{~mm}$ thickness and 3DK was used as substrate. Circuit board was prepared by milling technique. Peak efficiency of the designed amplifier is $44 \%$ at $5 \mathrm{~W}$ under continuous wave $(\mathrm{CW})$. Designed amplifier has more than $\% 40 \mathrm{PAE}$ in $50 \mathrm{MHz}$ bandwidth. According to results, designed amplifier has the highest efficiency and highest frequency in reported other Class $\mathrm{AB}$ amplifiers.
\end{abstract}

Keywords: GaN HEMT, RF Power Amplifier, Class AB Amplifier. 


\section{GíRiş̧}

Yüksek güçlü kuvvetlendiriciler, günümüzün $\mathrm{RF} /$ mikrodalga sistemlerinin temel bileşenlerindendir. Güç kuvvetlendiricileri uzun mesafeli iletişimde ya da radar gibi uygulamalarda, yüksek güçlü işaretlerin gerekli olduğu durumlarda genelde antenden önce yer alır. Çıkış gücünün yüksek olmasından dolayı güç kuvvetlendiricileri genelde kullanıldıkları sistemlerde en yüksek güç tüketen devrelerdir ve sistemin verimini belirleyen baskın elemandır.

Güç kuvvetlendiricilerinin en önemli teknik özellikleri kazanç, doğrusallık, verim ve çıkış gücü seviyesidir. Bu özelliklerin hepsinin en iyi olacağı bir devreyi gerçeklemek mümkün olmadığı için kullanılacak uygulamada hangi özelliğin daha önemli olduğuna bağlı olarak dengeli bir tasarım yapılır.

Genelde $20 \mathrm{dBm}$ üzerinde çıkış gücüne sahip kuvvetlendiricilerde büyük işaretler söz konusu olduğu için kuvvetlendiricilerin sınıfına göre tasarım ve test yöntemleri de değişmektedir. Günümüzde birçok tranzistor üreticisi, bilgisayar destekli tasarımlar için yüksek çıkış gücü verebilen tranzistorlarin doğrusal olmayan modellerini tasarımcılara sunmaktadır. Bu modeller ile belli kısıtlar altında bilgisayar ortamında tasarım yapılabilmektedir. Böylece henüz tasarım aşamasındayken yüksek gücün etkisinden kaynaklı etkiler kısmen de olsa incelenebilmektedir.

Yarıiletken teknolojilerindeki gelişmelerden olan galyum nitrit tabanlı tranzistorlar yüksek güçlü kuvvetlendiricileri de doğrudan etkilemiştir. Bant aralığı (band gap) yüksek bu tranzistorlar ile kırılma gerilimi yüksek tranzistorlar üretilebilmiştir. Daha yüksek güç üretebilme yeteneği ve daha iyi 1sı iletkenliği sayesinde yeni nesil yüksek güçlü ve yüksek frekanslı sistemlerde GaN HEMT yapılar sıklıkla kullanılmaya başlanmıştır (Moore ve Jimenez, 2014). 
Bu çalışmada, $2.4 \mathrm{GHz}$ frekansında çalışan $5 \mathrm{~W}$ çıkış gücüne sahip bir kuvvetlendirici, GaN HEMT kullanılarak ve doğrusal olmayan tranzistor modelinden yararlanılarak tasarlanmıştır. Çalışmanın ilk kısmında güç kuvvetlendiricileri hakkında temel bilgiler verilmiştir. İkinci kısmında tasarımda kullanılan yöntem ve gerekli hesaplamalar verilmiştir. Son olarak üretilen devre ile yapılan ölçüm sonuçları verilmiş ve sonuçlar değerlendirilmiştir.

\section{RF GÜÇ KUVVETLENDİRICİ TEMELLERİ}

Yüksek güçlü kuvvetlendiricilerde çıkış gücü, yüke aktarılan güç olarak tanımlanır. Kuvvetlendiriciler doğru akım ve gerilim ile beslenir ve çıkış gücünün besleme gücüne oranı verim olarak tanımlanır. Yüksek güçlü kuvvetlendiricilerde giriş gücü seviyesi de yüksek olacağı için yüksek güçlü kuvvetlendiricilerde eklenmiş verimi (power added efficiency) kullanmak daha uygundur (İfade 2.1). Eklenmiş verim hesabında giriş gücü çıkış gücünden çıkarılmaktadır. Güç kazancı da çıkıştaki gücün girişteki güce oranıdır (İfade 2.2). Genel bir yapı Şekil 2.1'de verilmiştir.

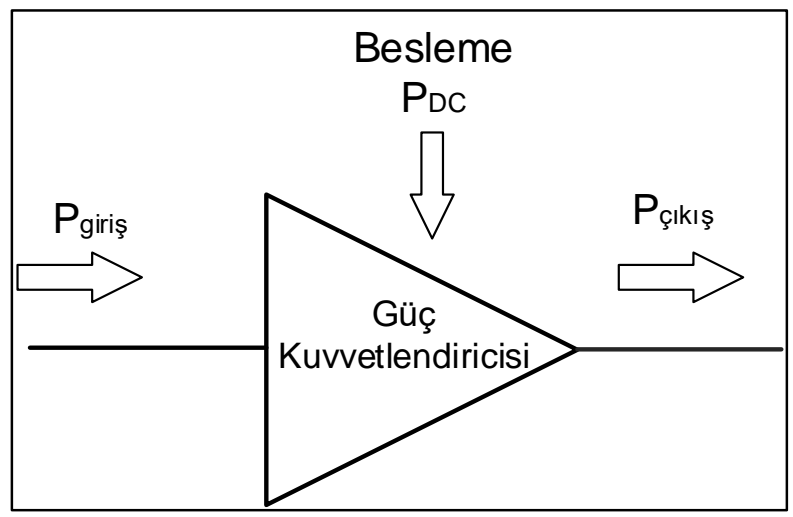

Şekil 2.1. Güç kuvvetlendiricisi giriş ve çıkışları

Eklenmiş Verim, $\eta_{\text {ek }}=\frac{P_{\text {çlkış }}-P_{\text {giriş̧ }}}{P_{D C}}$ 


$$
\text { Güç Kazancl, } \mathrm{G}_{\text {güç }}=\frac{\mathrm{P}_{\text {çıkış }}}{\mathrm{P}_{\text {giriş }}}
$$

Yüksek güçlü kuvvetlendiricilerde belirli bir noktaya kadar çıkış gücü arttıkça, verim de artar (Colantonio, Giannini ve Limiti, 2009). Fakat kuvvetlendirici doyma bölgesine girdikten sonra, kuvvetlendiricinin kazancı ve verimi düşer, doğrusallığı da bozulmaya başlar. Bu nedenle tasarım sırasında kazanç, çıkış gücü, verim ve doğrusallık arasında bir tercih yapılması gereklidir. Güç kuvvetlendiricilerin özelliklerini belirleyen etkenler kutuplama gerilimleri ve devre yapısıdır. Bu durum göz önüne alındığında, kuvvetlendiriciler genel olarak kutuplama türüne ve çalışma yapısına göre 2 ana sınıfa ayrılabilir (Colantonio, Giannini ve Limiti, 2009). A, AB, B ve C gibi kuvvetlendiriciler kutuplamaya bağlı kuvvetlendiricilerdir. $\mathrm{Bu}$ tür kuvvetlendiricilerin tasarımları daha kolay olup devre karmaşıklıkları da azdır. D, E, F, J tipi kuvvetlendiriciler de dalga şekillendirmeye dayalı olarak çalışmaktadır. Bu tür kuvvetlendiriciler savak üzerindeki akımın ya da gerilimin şekillendirilerek daha yüksek verim elde edildiği kuvvetlendiricilerdir. Devre tasarımları ve karmaşıklığı fazladır. Ancak kutuplamaya dayalı kuvvetlendirici tiplerine göre daha yüksek verim ve doğrusallığa sahip olabilmektedirler.

$\mathrm{Bu}$ çalışmada yüksek çıkış gücü ve yüksek kazanç istendiği için kuvvetlendirici AB sınıfı kutuplama ile tasarlanmıştır. Bu sayede verimden bir miktar kaybedilmesine rağmen kazanç seviyesi olabildiğince yüksek tutulmaya çalışılmıştır. Devrenin doğrusallığg da arttırılmıştır.

\section{TASARIM}

Yüksek güçlerde kuvvetlendiricilerin giriş ve çıkışında büyük genlikli işaretler bulunduğu için giriş ve çıkış empedansları frekansa ve güce bağlı olarak büyük değişiklik gösterebilmektedir. Belirlenen 
frekans ve güçte en verimli ya da en yüksek çıkış gücü elde edebilmek için gerekli savak ve geçit empedans değerleri Yük/Kaynak-Çekim (Source/Load-Pull) analizi ile belirlenebilir. Normalde tranzistor üzerinde ölçüm yaparak uzun sürede yapılabilen bu analizler, gelişen doğrusal olmayan tranzistor modelleriyle bilgisayar destekli tasarım araçları sayesinde hızlı bir şekilde yapılabilir. Özellikle, modellerin daha geniş bant ve besleme gerilimi aralığında incelemeye imkan vermesi, tasarım aşamasında daha geniş aralıkta analiz yapılmasını sağlamaktadır.

Yüksek güçte ve yüksek frekansta çalışabilen tranzistorlar paketlendiğinde (Şekil 3.1) bağlantı noktaları ve paketin malzemesinden kaynaklı parazitik etkiler de göz önüne alınmalıdır. Doğrusal olmayan modeller, paket kaynaklı parazitik etkileri de içerecek şekilde hazırlanmaktadır.

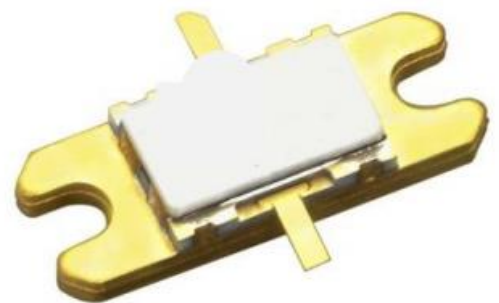

Şekil 3.1. Tasarımda kullanılan paketlenmiş haldeki SGNE010MK tranzistoru (Sedi, 2012)

Çalışmada NI AWR Microwave Office tasarım aracı kullanılarak Sumitomo Electric firmasının sağladığı doğrusal olmayan model ile yük-çekim analizi yapılmıştır. Kuvvetlendirici $50 \mathrm{~V}$ gerilim ile kutuplanmış ve sükunette $100 \mathrm{~mA}$ akım akıtacak şekilde geçit gerilimi ayarlanmıştır. Bilgisayar destekli analizde ilk 3 harmonik uygun sonlandırılarak gerekli empedans değerleri bulunmuştur. Harmonik empedanslarının sonlandırımı için kayıpsız ideal empedans uydurucu kullanılmıştır (Şekil 3.2). İlk 3 harmoniğin uygun sonlandirılması durumunda ideal olarak \%77 verim elde edilebileceği görülmüştür. 


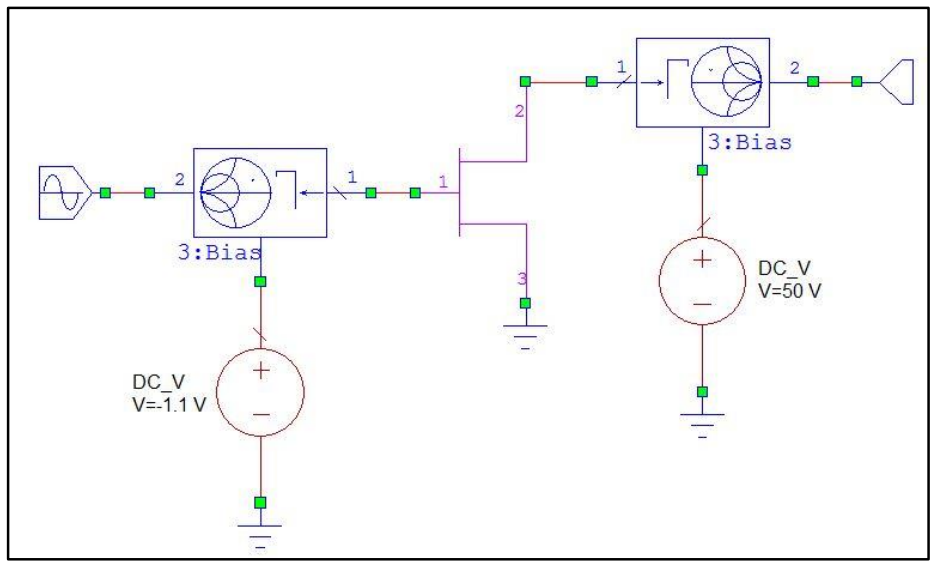

Şekil 3.2. NI AWR ile yük/kaynak-çekim analizi (Load\&source pull analysis by NI AWR MWO)

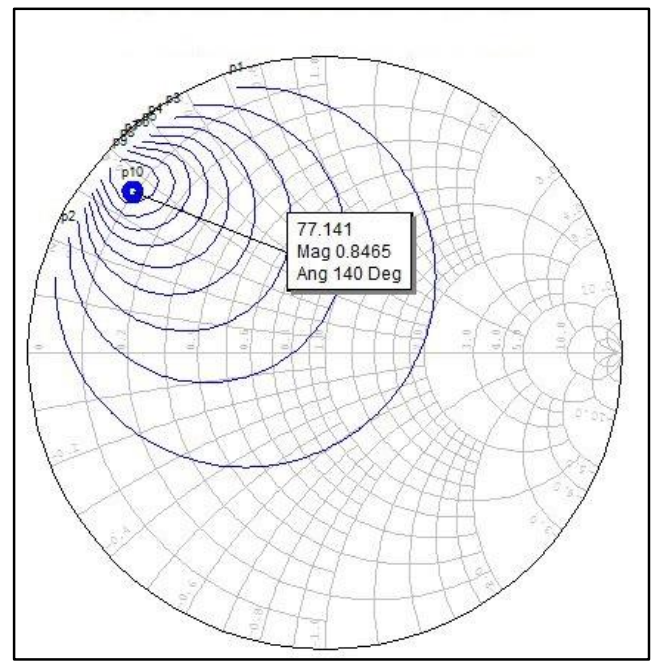

Şekil 3.3. İdeal durumda yük-çekim analizinde elde edilen verim

\subsection{Devre Yapısı}

Bütün harmoniklerin uygun sonlandırılması verimi arttıran bir tasarım şekli olsa da devre karmaşıklığını arttırdığı için bu çalışmada tercih edilmemiştir. Devre tasarımına ilk olarak kutuplama devresinin tasarımı ile başlanmıştır. Tasarımda Taconic TSM DS3 0300-CL1/CL1 tabanı kullanılmıştır. Bu tabanın dielektrik sabiti 3, kayıp tanjantı 0.0011 ve kalınlığ 0.76 mm'dir. Çeyrek dalga boyu uzunluğunda mikroşerit hat ile tranzistorun geçit ve savak kutuplama 
gerilimi sağlanmıştır (Şekil 3.4). Hattın sonu bir kondansatör ile yüksek frekanslar açısından kısa devre edildiğinde A noktasından DC kaynağa doğru görülen empedans $f_{o}$ merkez frekansı için teorik olarak sonsuz olacaktır (Grebennikov, 2014). 2. harmonik frekansında ise $\lambda / 2$ hat gibi davranacağı için 2. harmonik açısından incelendiğinde A noktasından DC kaynağa doğru bakıldığında kısa devre gibi davranacaktır. Çeyrek dalga boyu uzunluğundaki hat ile yapılan kutuplama devresinin ardından merkez frekansta en yüksek verim için empedans uyumu yapılmıştır. Mikroşerit hatların empedansları çok yüksek seçilmemiştir. Bu nedenle yüksek akım ve gerilim taşıyabilecek fiziksel yeterlikte olmaları sağlanmıştır.

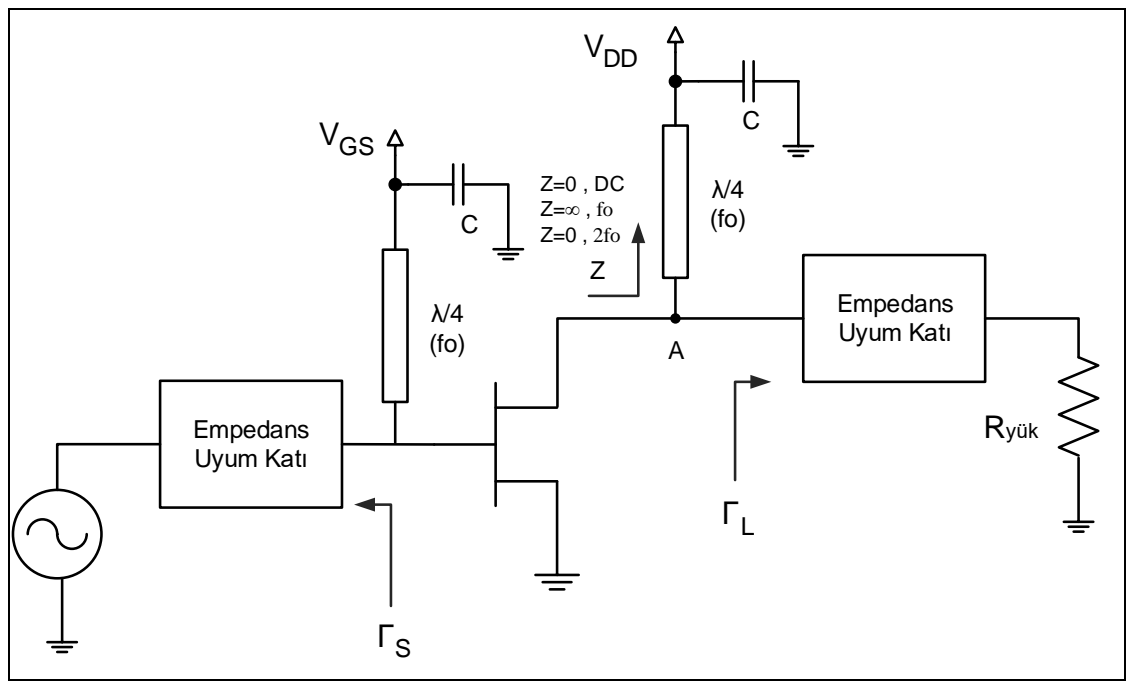

Şekil 3.4. Tasarımda kullanılan devre ve kutuplama yapısı

Kutuplama yapısında 2. ve 3. harmonik frekanslarında kisa devreye yakın etki gösterecek kondansatör değerlerini ayrık elemanlar ile sağlamaya çalışmak kondansatörlerin yüksek frekanstaki davranışları ele alındığında çok uygun değildir. Bu çalışmada ikinci ve üçüncü harmonik frekanslarında yüksek değerli kapasite etkisi oluşturacak radyal yan hat kullanımı tercih edilmiştir. Bu hatlardan 2 adet kullanılarak 2 . ve 3 . harmonik için ayrı ayrı tasarım yapılmış ve çeyrek dalga uzunluğundaki hattın hemen sonuna bağlanmıştır 
(Şekil 3.5). Daha küçük frekanslardaki gürültüleri önlemek için bir kondansatör de kullanılmıştır.

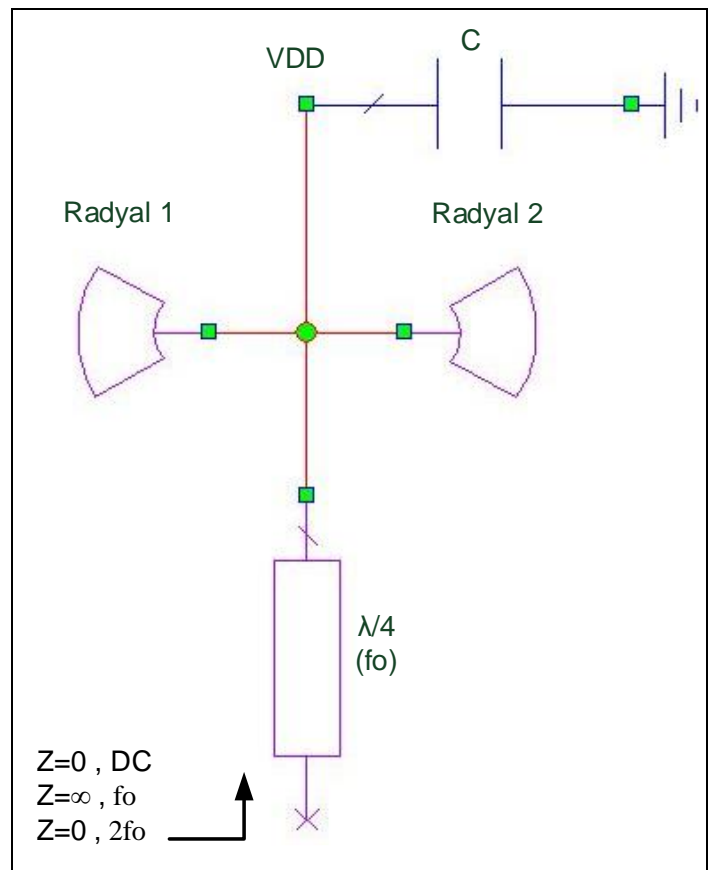

Şekil 3.5. Mikroşerit yapılı besleme hattı

\subsection{Devre Tasarımı ve Analizi}

Kutuplama yapısı eklenerek yeniden yapılan yük ve kaynak çekim analiziyle giriş ve çıkışta kullanılması gereken empedans uydurucular için yansıma katsayıları $0.79\left\llcorner 2.65^{\circ}\right.$ ve $0.834\left\llcorner-169^{\circ}\right.$ olarak belirlenmiştir. Empedans uyumunu sağlayacak şekilde yapılan devre Şekil 3.6' da verilmiştir. Bu durumda elde edilen verim ve çıkış gücü grafiği de Şekil 3.7 ve 3.8 'de görülmektedir. Devre elemanı değerleri ve mikroşerit hatların uzunlukları Tablo 3.1.'de verilmiştir. 


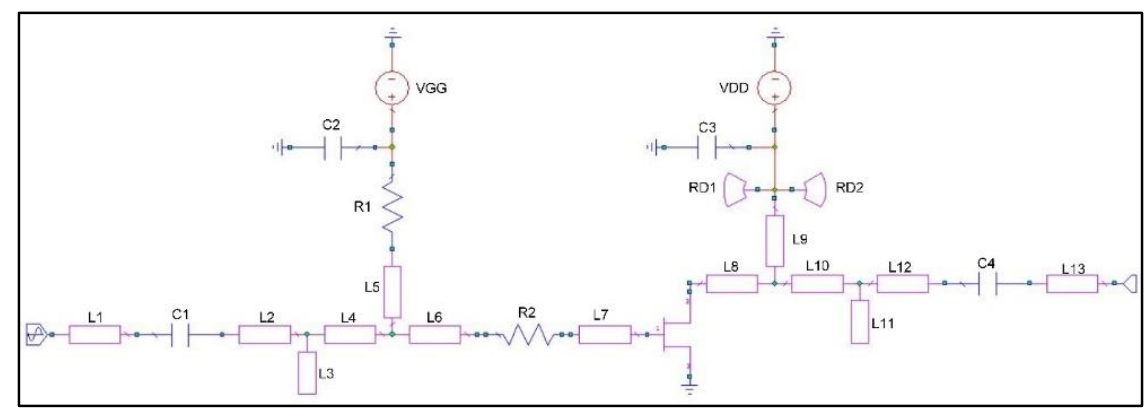

Şekil 3.6. NI AWR MWO ile tasarlanan devre

Tablo 3.1. Tasarlanan devredeki devre elamanları ve mikroşerit hatlar

\begin{tabular}{|c|c|c|c|c|c|c|c|c|}
\hline $\begin{array}{c}\text { Devre } \\
\text { Elemanı }\end{array}$ & Değer & $\begin{array}{c}\text { Devre } \\
\text { Elemanı }\end{array}$ & $\begin{array}{c}\text { Genişlik } \\
(\mathrm{mm})\end{array}$ & $\begin{array}{c}\text { Uzunluk } \\
(\mathrm{mm})\end{array}$ & $\begin{array}{c}\text { Devre } \\
\text { Elemanı }\end{array}$ & $\begin{array}{c}\mathrm{Ri} \\
(\mathrm{mm})\end{array}$ & $\begin{array}{c}\text { Ro } \\
(\mathrm{mm})\end{array}$ & Açı \\
\hline R1 & $56 \Omega$ & L1 & 1.87 & 9 & RD1 & 0.94 & 5.6 & 29.4 \\
\hline R2 & $0.5 \Omega$ & L2 & 1.87 & 2 & RD2 & 0.24 & 6.1 & 63.4 \\
\hline C1 & $22 \mathrm{pF}$ & L3 & 3.9 & 9.5 & & & & \\
\hline $\mathrm{C} 2$ & $10 \mathrm{nF}$ & L4 & 1.87 & 5 & & & & \\
\hline C3 & $10 \mathrm{nF}$ & L5 & 0.4 & 20 & & & & \\
\hline $\mathrm{C} 4$ & $22 \mathrm{pF}$ & L6 & 3 & 3 & & & & \\
\hline & & L7 & 4 & 4 & & & & \\
\hline & & L8 & 1.5 & 1.5 & & & & \\
\hline & & L9 & 20 & 20 & & & & \\
\hline & & L10 & 7 & 7 & & & & \\
\hline & & L11 & 5.5 & 5.5 & & & & \\
\hline & & L12 & 10.6 & 10.6 & & & & \\
\hline & & L13 & 15 & 15 & & & & \\
\hline
\end{tabular}




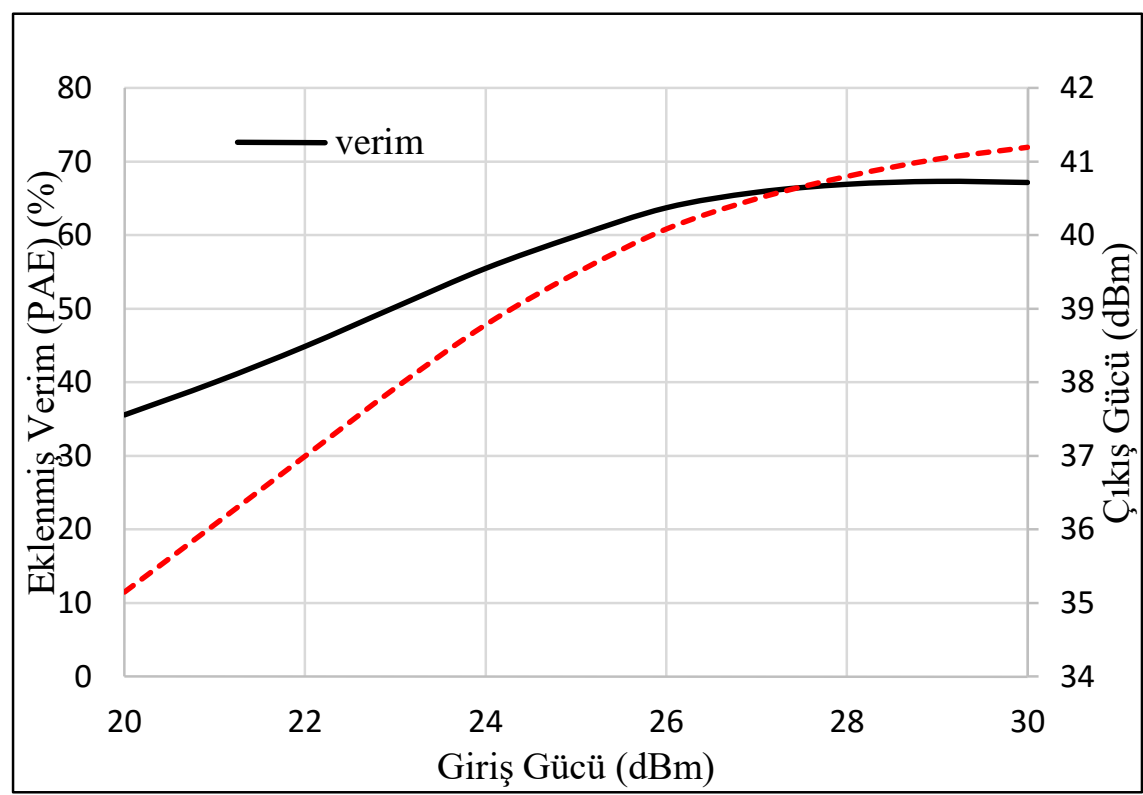

Şekil 3.7. Tasarlanan devrenin 2.4 GHz'deki çıkış gücü ve verimi (düz çizgi eklenmiş verim, kesikli çizgi çıkış gücü)

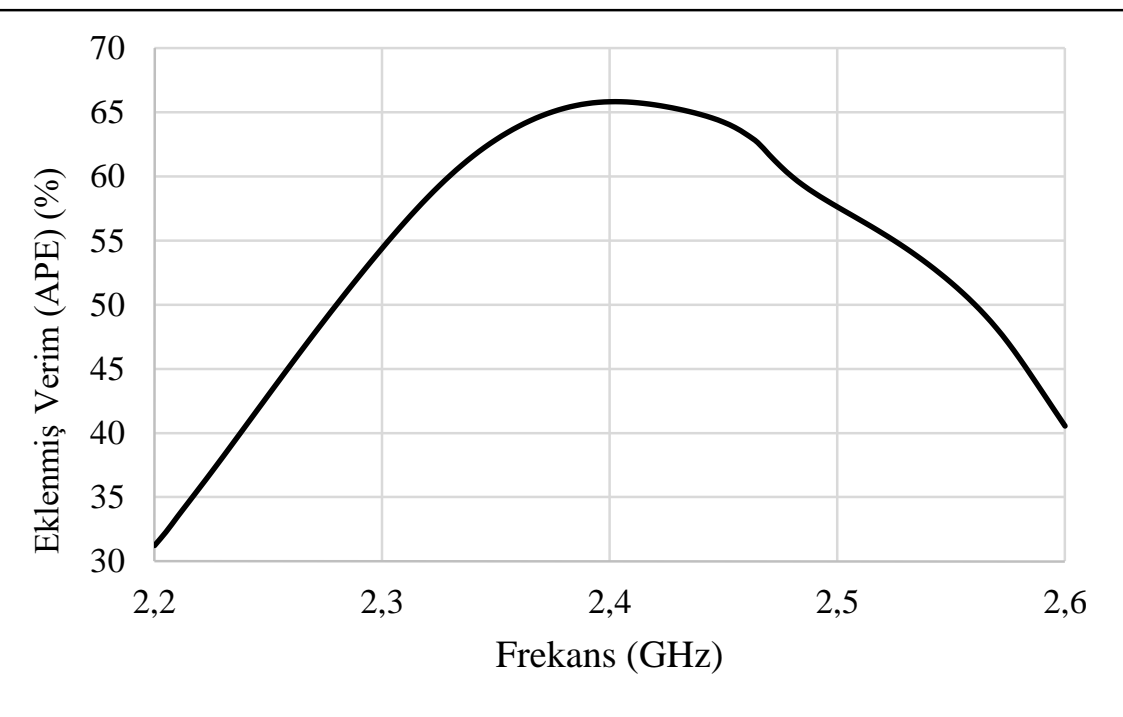

Şekil 3.8. Tasarlanan devrenin frekansa bağlı verim grafiği (giriş gücü $27 \mathrm{dBm}$ ) 


\section{4. ÖLÇÜM SONUÇLARI}

Bilgisayar destekli tasarımın ardından devre serimi hazırlanmış ve elektronik devre kartı üretilmiştir. Devre kartlarının üretimi kazıma yöntemiyle laboratuvarda yapılmıştır. Devrenin boyutu $73.4 \mathrm{~mm} \mathrm{x}$ 82.6 mm'dir. Devre giriş ve çıkışında SMA dişi konnektör kullanılmıştır. Devre kartları ve tranzistor 1sı dağıtımı sağlamak için metal üzerine yerleştirilmiştir (Şekil 4.1). Ölçümler sürekli işaret ile yapılmıştır. Bu nedenle 1sınma etkisi de ölçümlere dahil edilmiştir. Ölçüm sonucunda $2.4 \mathrm{GHz}$ frekansında \%44 verim elde edilmiştir (Şekil 4.2). $50 \mathrm{MHz}$ bant genişliğinde $\% 40$ üzerinde verim sağlanmaktadır. $1 \mathrm{MHz}$ aralıklı işaret kullanılarak yapılan 2 ton testinde de ölçülen fark yaklaşık $25 \mathrm{dBc}$ 'dir.

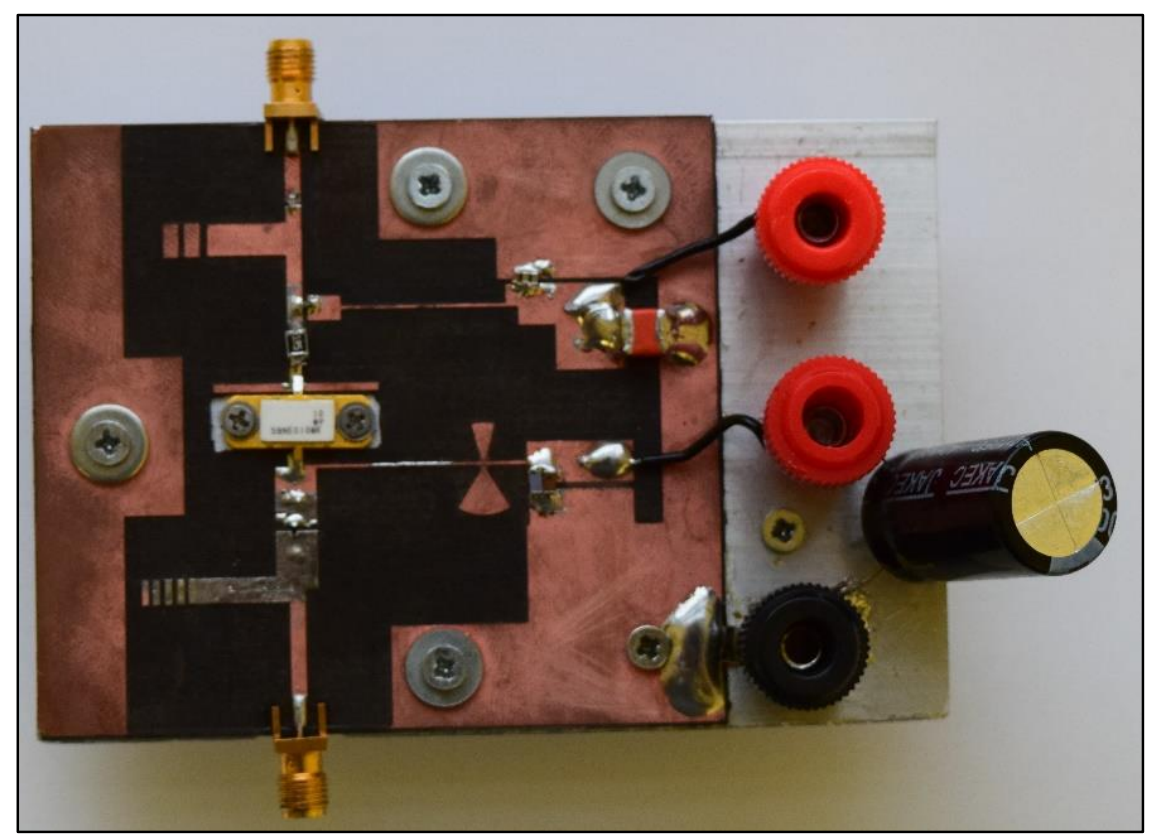

Şekil 4.1. Üretilen devre 


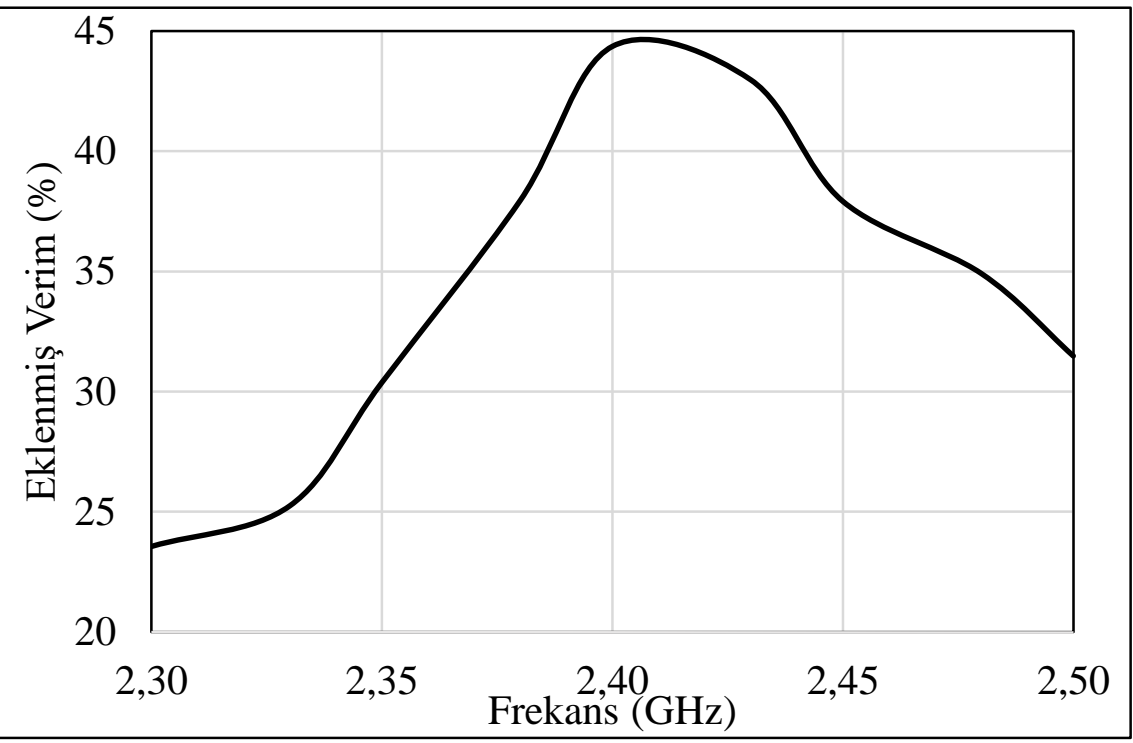

Şekil 4.2. Verimin frekansla değişimi

Tablo 4.1, raporlanan çalışmaları ve bu çalışmaların sonuçlarını göstermektedir. Tasarlanan kuvvetlendirici, AB sınıfında tasarlanan diğer kuvvetlendiricilere göre, daha yüksek frekansa ve daha yüksek verime sahiptir.

Tablo 4.1. Literatürdeki benzer çalışmalar ve sonuçları

\begin{tabular}{|c|c|c|c|c|c|}
\hline Tasarım & $\begin{array}{l}\text { Frekans } \\
\text { Aralığı }\end{array}$ & $\begin{array}{l}\text { Ç1k1ş } \\
\text { Gücü }\end{array}$ & Sinif & Verim & Tranzistör \\
\hline Shumaker & $0.3-1.1 \mathrm{GHz}$ & $15 \mathrm{~W}$ & $\mathrm{AB}$ & $\% 40$ & SGNE010MK \\
\hline Taş ve diğ., 2012 & $1.8 \mathrm{GHz}$ & $2.4 \mathrm{~W}$ & $\mathrm{AB}$ & $\% 23.24$ & CGH40010 \\
\hline Azam ve diğ., 2008 & $0.7-1.8 \mathrm{GHz}$ & $13.5 \mathrm{~W}$ & $\mathrm{AB}$ & $\% 32$ & SGNE010MK \\
\hline Bu çalışma & $2.4 \mathrm{GHz}$ & $5 \mathrm{~W}$ & $\mathbf{A B}$ & $\% 44$ & SGNE010MK \\
\hline Kim ve diğ., 2007 & $1.7 \mathrm{GHz}$ & $9.8 \mathrm{~W}$ & B & $\% 69.2$ & CGH40010 \\
\hline Kim ve diğ., 2008 & $2.14 \mathrm{GHz}$ & $10 \mathrm{~W}$ & Doherty & $\% 52.4$ & SGNE010MK \\
\hline Bae ve diğ., 2007 & $2 \mathrm{GHz}$ & $11.4 \mathrm{~W}$ & $\mathrm{E}$ & $\% 74$ & SGNE010MK \\
\hline Moon ve diğ., 2008 & $2.14 \mathrm{GHz}$ & $32.6 \mathrm{~W}$ & $\begin{array}{l}3 \text { Yollu } \\
\text { Doherty }\end{array}$ & $\% 63$ & SGNE010MK \\
\hline
\end{tabular}




\section{SONUÇ}

$\mathrm{Bu}$ çalışmada AB sınıfı bir RF güç kuvvetlendiricisi tasarlanmış ve gerçeklenmiştir. Kuvvetlendiricide Sumitomo SGNE010MK GaN HEMT kullanılmıştır ve kuvvetlendirici sürekli işaret ile yapılan ölçümlere göre $5 \mathrm{~W}$ çıkış gücünde $\% 44$ verime sahiptir. $1 \mathrm{MHz}$ aralıklı işaret ile yapılan 2 ton testinde, fark yaklaşık $25 \mathrm{dBc}$ olarak ölçülmüştür. Bu kuvvetlendirici, aynı tranzistör ile tasarlanmış olan ve raporlanmış $\mathrm{AB}$ sınıfı güç kuvvetlendiricilerine göre daha yüksek frekansta daha yüksek verime sahiptir.

Kuvvetlendiricinin modeli kullanılarak yapılan bilgisayar destekli tasarım analizinde elde edilen verim ile ölçülen arasında yaklaşık $\% 20$ fark bulunmaktadır. Fark oluşumunun iki önemli sebebi olduğu öngörülmektedir. Bu sebeplerden ilki, tasarımda kullanılan doğrusal olmayan tranzistor modelinin 1sınma etkisini kapsayan bir özelliği olmamasıdır. İkinci neden ise, modelin sınır değerlerinin belirtilmemiş olmasıdır. Güç kuvvetlendirici uygulamalarında harmoniklerin doğru bir şekilde incelenmesi gerekir. Fakat temin edilen modelin hangi frekans aralığını desteklediği bilinmemektedir. Ayrıca yüksek sıcaklıkta güç tranzistorlerinin kazançları da çok değişeceği için verim doğrudan etkilenmektedir. Elektronik devre kartı üretimi için kullanılan kazıma tekniğinin hassasiyeti ve montaj kaynaklı sapmalar da bu farklılıkta bir miktar paya sahiptir.

\section{KAYNAKLAR}

[1] Azam, S., Jonsson, R. ve Wahab, Q., "Designing, Fabrication and Characterization of Power Amplifiers Based on 10-Watt SiC MESFET \& GaN HEMT at Microwave Frequencies", 38th European Microwave Conference, 27-31 Ekim 2008, 444-447.

[2] Bae, H.G., Negra, R., Boumaiza, S. ve Ghannouchi, F.M., "Highefficiency GaN class-E power amplifier with compact harmonicsuppression network", European Microwave Conference, 9-12 Ekim 2007, 1093-1096. 
[3] Colantonio, P., Giannini, F. ve Limiti, E., High Efficiency RF and Microwave Solid State Power Amplifier, John Wiley \& Sons, GB, 2009.

[4] Grebennikov, AV., RF and Microwave Power Amplifier Design, McGraw-Hill, New York, 2014.

[5] Kim B., Derickson, D. ve Sun, C., "A High Power, High Efficiency Amplifier using GaN HEMT", Asia Pasific Microwave Conference, 2007, 11-14 Aralık 2007.

[6] Kim, J., Moon, J., Woo, Y., Hong, S., Kim, I., Kim J., ve Bumman, Kim., "Analysis of a Fully Matched Saturated Doherty Amplifier With Excellent Efficiency", IEEE Microwave Theory and Techniques, Cilt 56, No 2, 2008, 328-338.

[7] Moon, J.; Kim, J.; Kim, I.; Kim, J.; Kim, B., "Highly Efficient ThreeWay Saturated Doherty Amplifier With Digital Feedback Predistortion," Microwave and Wireless Components Letters, IEEE, vol.18, no.8, Aug. 2008, s.539-541.

[8] Moore, A. ve Jimenez, J., GaN RF Technology for Dummies, Triquint Special Edition, John Wiley \& Sons, Hoboken NJ, 2014.

[9] Sedi. (2012). SGNE010MK data sheet. http://www.sedi.co.jp/pdf/SGNE010MK_ED1-0.pdf , 5 Ekim 2014 tarihinde alınmıştır.

[10] Shumaker, J., "A 10-Watt Multi-Octave Power Amplifier Design Using the EGN010MK GaN Device", Sumitomo Electric Device Innovations, USA

[11] Taş, D., Ceylan, O. ve Yağcı, H., “A GaN HEMT Class AB RF Power Amplifier", 12. Mediterranean Microwave Symposium, İstanbul, Eylül 2012. 